\title{
Differential Expression of Toll like Receptor 4 in Type 2 Diabetic Patients with Impaired Wound Healing
}

\author{
Kanhaiya ${ }^{1}$, Agrawal NK ${ }^{2}$, Gupta $\mathrm{SK}^{3}$ and Kiran Singh ${ }^{1 *}$
}

${ }^{1}$ Department of Molecular and Human Genetics, Banaras Hindu University, India

${ }^{2}$ Department of Endocrinology and Metabolism, Institute of Medical Sciences, Banaras Hindu University, India

${ }^{3}$ Department of Surgery, Institute of Medical Sciences, Banaras Hindu University, India

\begin{abstract}
Toll like Receptor 4 (TLR4), is known for its key role in initiation of innate immunity and regulation of adaptive immune responses. TLR4 is also an important regulator of wound inflammation, stimulator of growth factors like vascular endothelial growth factor (VEGF) and plays an important role in restoring damaged tissue integrity during normal wound healing. In the present study we have investigated 78 Diabetic Foot ulcer (DFU) patients with Type 2 diabetes (T2DM) and 8 foot ulcers patients without T2DM as controls for the differential expression of TLR4 both at mRNA level and protein level. Expression analysis was done using semi-quantitative RT-PCR, quantitative Real-time PCR and western blot. TLR4 message and protein were significantly down-regulated in DFU patients as compared to controls. Similarly down regulation of VEGF was also observed in DFU patients as compared to controls. DNA Methylation is an important regulator of gene expression therefore Methylation status of promoter of TLR4 gene was analyzed in DFU and control wounds using specific methylation-sensitive restriction enzyme which suggested higher methylation of TLR4 promoter in DFU with respect to controls. TLR4 expression was not influenced by the infection status and wound grade of the subjects however TLR4 was significantly affected by the gender of the subjects. These results clearly suggests that TLR4 down regulation in the wounds of T2DM subjects could be one of the causes contributing to impairment in healing of diabetic wounds and eventually into the development of chronic, non healing ulcers in T2DM subjects.
\end{abstract}

Keywords: Diabetic foot ulcer; T2DM; Wound healing impairment

Abbreviations: TLR4: Toll Like Receptor 4; VEGF: Vascular Endothelial Growth Factor

\section{Introduction}

Persistent hyperglycemia in Type 2 Diabetes (T2DM) is the proximal determinant of initiating and regulating the chain of abrupt biochemical and physiological changes. Unresolved wound healing is one of the several complications due to T2DM, representing a huge health care expenditure even in most developed countries $[1,2]$. Other complications of T2DM like neuropathy, tissue hypo-perfusion and diminished local response to infection also contribute a lot in unfavorable wound healing cascade [3]. Mammalian tissues are generally repaired rather being regenerated during the process of wound healing. The normal wound healing procedure is a cascade of distinct but mutually overlapping stages viz. homeostasis, acute inflammation, proliferation and remodeling $[4,5]$. The innate immune system has a major role to play in an efficient wound healing cascade and is generally mediated by Toll like Receptors (TLRs) and their downstream effector molecules [6]. This response is antigen independent and via regulation of several chemokines and cytokines they also serve as first line of anti microbial defense [7]. TLRs in mammalian system are the homologue to drosophila Toll receptors which were first discovered in 1985 by Christiane Nusslein- Volhard [8]. In Drosophila these Toll receptors are involved in embryonic development and evasion from fungal infection $[9,10]$. TLR4 was the first discovered member of the TLR family and it is associated with induction of a wide spectrum of cytokines [7].

TLR4 due to its additional roles in immnostimulation [11], modulation of inflammation [12], angiogenesis [13], and tissue repair and regeneration [14] has recently being shown to be a vital molecule in wound healing [6]. Wounds devoid of TLR4 or its downstream targets like MyD88, take longer time to heal and often develop into chronic non healing ulcers [15]. TLR4 lies upstream to various growth factors involved in proper wound healing. One of the potent growth factor is Vascular Endothelial Growth Factor (VEGF) which is an active member of wound healing cascade due to its role as a mitogen for endothelial cells and inducer of vascular permeability [16]. VEGF potentially promotes multiple phases of wound healing like angiogenesis, wound re-epithelization and collagen deposition [17]. Functional TLR4 is also responsible for the expression and regulation of VEGF $[18,19]$. Hence diminished expression of TLR4 in diabetic wounds may abrogate wound healing due to inappropriate expression and function of VEGF. Considering these histo-protective nature of TLR4, we hypothesized that differential expression of TLR4 may be contributing to the impaired healing ulcers in lower extremity of T2DM patients. This down regulation of TLR4 may also lead to lower expression levels of VEGF. Hence we analyzed the expression of TLR4 in wounds of DFU patients with T2DM compared to the wounds of non diabetic controls both at transcriptional level as well as protein level. We also quantified the mRNA transcripts of VEGF to evaluate if this down regulation of TLR4 in T2DM patients is affecting the levels of VEGF. Our results show that DFU patients have low expression of TLR4 and VEGF, which could lead to non-healing ulcers in T2DM individuals due to impairment of wound healing process.

*Corresponding author: Kiran Singh, Department of Molecular and Human Genetics, Banaras Hindu University, Varanasi-221005, India, Tel: +919454210058; Fax: +91-542-670-2499; E-mail: skiran@bhu.ac.in

\section{Received March 25, 2013; Accepted April 22, 2013; Published April 26, 2013}

Citation: Kanhaiya, Agrawal NK, Gupta SK, Kiran Singh (2013) Differential Expression of Toll like Receptor 4 in Type 2 Diabetic Patients with Impaired Wound Healing. J Diabetes Metab 4: 260. doi:10.4172/2155-6156.1000260

Copyright: ( 2013 Kanhaiya, et al. This is an open-access article distributed under the terms of the Creative Commons Attribution License, which permits unrestricted use, distribution, and reproduction in any medium, provided the original author and source are credited. 


\section{Materials and Methods}

\section{Subjects}

A total of 86 lower extremity wounds were analyzed, out of which 78 were DFU cases and 8 were controls with acute wounds and without having T2DM. Wound sampling was done from the margins of the wounds. Wounds were classified on the basis of the Wagner Grading System [20]. The presence and absence of infection in the wounds were also recorded. Samples were collected from the OPD clinics and operation theatres of Department of Endocrinology and Metabolism and Department of Surgery, Institute of Medical Sciences, Banaras Hindu University, Varanasi, India. DFU Patients underwent a standardized clinical and laboratory evaluation (Table 1). Each patient's family history, habits (smoking, alcoholism etc.) and disease were recorded through a questionnaire. Informed consent was obtained from all the subjects to carry out molecular analysis. Institutional ethical committee approval was obtained.

\section{Semi-quantitative RT-PCR}

Total RNA was isolated from wounds samples using TRIzol reagent followed by DNase treatment. cDNA was synthesized and semi-quantitative RT-PCR analysis of TLR4 was done in 78 DFU cases and 8 controls as described. For TLR4 expression, PCR was performed with forward primer 5'- CAGAGTTTCCTGCAATGGATCA -3' and the reverse primer 5'- GCTTATCTGAA GGTGTTGCACAT -3 ', resulting in $85 \mathrm{bp}$ fragment. The PCR conditions were initial denaturation step of $94^{\circ} \mathrm{C}$ for $5 \mathrm{~min}$ followed by 30 cycles of $30 \mathrm{sec}$ at $94^{\circ} \mathrm{C}, 40 \mathrm{sec}$ at $58^{\circ} \mathrm{C}, 40 \mathrm{sec}$ at $72^{\circ} \mathrm{C}$ and then a final extension step of $10 \mathrm{~min}$ at $72^{\circ} \mathrm{C}$. Glyceraldehyde 3-phosphate dehydrogenase (GAPDH) expression level was checked as an internal control to ascertain the quality of cDNA. Primers used for GAPDH were: GAPDH forward 5'-CATGAGAAGTATGACAACAGC -3', GAPDH reverse 5'-AGTCCTTCCACGATACCAAAG -3'. Expression of TLR4 transcript was quantified after normalization of samples using GAPDH gene.

\section{Quantitative Real-time PCR}

A real time quantitative polymerase chain reaction (RTqPCR) experiment was performed to validate the results obtained by semi quantitative RT- PCR approach. cDNA samples of 43 DFU cases and 8 controls were randomly selected and used for RT-qPCR experiment. Real-time PCR was done according to the manufacturer's protocol (Applied Biosystem). The following primers were used: TLR4 forward 5'- CAGAGTTTCCTGCAATGGATCA -3', TLR4 reverse 5'- GCT TATCTGAAGGTGTTGCACAT -3', VEGF forward 5'-TGCAGATTAT GCGGATCAAAC -3', VEGF reverse 5'-TGCATTCACATTTGTTGTGCT 3', GAPDH forward 5'-CATGAGAAG TATGACAACAGC -3', GAPDH reverse 5'-AGTCCTTCC ACGATACCAAAG -3'. Briefly, $20 \mu$ total reaction volume containing $10 \mu \mathrm{l}$ SYBR Green master mix (Applied Biosystem), $0.1 \mu \mathrm{l}$ each forward and reverse primer $(10 \mathrm{pM} / \mu \mathrm{l})$ and $2 \mu \mathrm{cDNA}$ was used in PCR using ABI 7500 instrument. PCR was performed with an initial incubation at $50^{\circ} \mathrm{C}$ for $2 \mathrm{~min}$, followed by $10 \mathrm{~min}$ denaturation at $95^{\circ} \mathrm{C}$ and 40 cycles at $95^{\circ} \mathrm{C}$ for $15 \mathrm{~s}, 60^{\circ} \mathrm{C}$ for $1 \mathrm{~min}$ and $72^{\circ} \mathrm{C}$ for $40 \mathrm{~s}$. TLR4 and VEGF data were normalized to the mRNA levels of housekeeping gene GAPDH. $\triangle \triangle \mathrm{CT}$ and relative fold change of TLR4 and VEGF in DFU cases were calculated as described by Gireesh et al. [21].

\section{Western blot}

Western blot analysis was performed on whole-tissue extracts. 43 DFU cases and 8 controls were utilized for the proteomic analysis. Briefly, $100 \mu \mathrm{g}$ of protein was loaded on $13.5 \%$ SDS-PAGE gel, transferred to nitrocellulose membrane and blocked with $5 \%$ of skim milk in TBS. Total TLR4 was detected using the mouse monoclonal antiTLR4 antibody Abcam (Cambridge, MA; clone 76B357.1, Catalogue \# ab22048), then incubated with the secondary antibody linked to horseradish peroxidase. The immunoreactive bands were visualized by the Enhanced Chemiluminescence System (Amersham Biosciences). Blots were stripped off and reprobed with an anti-GAPDH antibody. Alpha Imager 2200 software version 3.1.2 was used to quantify band density.

\section{Methylation analysis of TLR4 promoter}

Genomic DNA was isolated from wound samples using Phenolchloroform method. The methylation status of TLR4 gene promoter was analyzed in 43 DFU and 6 controls according to a previous study by De Oliveira et al. [22]. It was a PCR based approach which relied on the inability of restriction enzyme to cut methylated sequences. Two sites were examined in the TLR4 promoter (Figures 1A and 1B) which was recognized by restriction enzyme AciI whose activity is always blocked by CpG methylation. $100 \mathrm{ng}$ of genomic DNA was completely digested with $2 \mathrm{U}$ of AciI in $5 \mu \mathrm{l}$ of sample containing water and buffer. After digestion $2.5 \mu \mathrm{l}(50 \mathrm{ng})$ of digested DNA was pipetted into $18 \mu \mathrm{l}$ of PCR master mix containing forward and reverse primers Forward 5'- AAAGGGGAAATGGGGAGTTA- 3' Reverse

\begin{tabular}{|l|c|}
\hline Average age & $54.92 \pm 9.42$ years \\
\hline Average BMI $\left(\mathrm{kg} / \mathrm{m}^{2}\right)$ & $21.93 \pm 2.92 \mathrm{Kg} / \mathrm{m}$ \\
\hline Average duration of type 2 diabetes in years & $10.76 \pm 4.6$ years \\
\hline Male & $55(70.5 \%)$ \\
\hline Female & $23(29.5 \%)$ \\
\hline Poor glycemic Control (FBS $>140 \mathrm{mg} / \mathrm{dl}$, PPBS $>180 \mathrm{mg} / \mathrm{dl})$ & $48(61.5 \%)$ \\
\hline Family history present & $10(12.8 \%)$ \\
\hline Nephropathy present (Serum creatinine $>1.4 \mathrm{mg} / \mathrm{dl})$ & $24(30.76 \%)$ \\
\hline Neuropathy present (by monofilament test) & $48(61.53 \%)$ \\
\hline Hypertension present (systolic BP $>140 \mathrm{~mm}$ of Hg) & $25(32.05 \%)$ \\
\hline Retinopathy present & $12(15.38 \%)$ \\
\hline Dislipidimea present (Serum cholesterol and Tgy levels $>200 \mathrm{mg} / \mathrm{dl})$ & $14(17.9 \%)$ \\
\hline Infection present (Wound culture positive for microbes) & $43(55.12 \%)$ \\
\hline Bone involvement (Osteomyelitis) & $27(34.61 \%)$ \\
\hline
\end{tabular}

Data are presented as mean \pm SD or as number (percentage).

Table 1: Biochemical and Demographic parameters of DFU patients $(\mathrm{N}=78)$ 
5'-TTTTGCAGGACACAATTTGG -3'. The non-enzyme-treated DNA sample was also amplified along with enzyme-treated samples as a positive control for the PCR reaction and for DNA loading, representing $100 \%$ of input DNA amplified after PCR (Figure 1C).

Intensity of the bands was calculated using software Alpha Imager. Non-digested samples were assumed to be $100 \%$ of total DNA amplification. Samples were classified into three groups: (i) methylated (band intensity equal to $100 \%$ to $75 \%$ that of undigested DNA), (ii) hemimethylated (band intensity equal to $25 \%$ to $75 \%$ that of undigested DNA) and unmethylated (band intensity less than 25\% of that of undigested DNA).

\section{Statistical analysis}

The data were expressed as mean with considering whiskers minimum to maximum. Statistical significance $(\mathrm{P}<0.05)$ was determined with Student's $t$ test (two-tailed) and non parametric ANOVA. Statistical analysis of data was performed using GraphPad Prism 5.01 and IBM SPSS Statistics 20.0 software.

\section{Result}

To analyze the difference in the mRNA transcripts of TLR4 in DFU cases as compared to controls, semi-quantitative RT-PCR approach was used. Figure 2 shows that the TLR4 mRNA expression was significantly down regulated in the lower extremity wounds of DFU T2DM patients compared to that of control wounds ( $\mathrm{p}$ value $=0.02, \mathrm{t}=2.28$, mean change in percent ratio $=0.99$, Standard error of mean=0.04). To validate the results obtained by semi-quantitative method, Quantitative Real-time PCR (RT-qPCR) was used in randomly selected 43 DFU and 8 controls. RT-qPCR analysis as shown in figure 2, further validates the down-regulation of TLR4 in diabetic wounds compared to control wounds ( $\mathrm{p}$ value $=<0.0001$, mean fold change $=-1.13$, Standard error of mean $=0.17$ ). Because VEGF, an important molecule in wound healing process is downstream of TLR4, we reasoned that decreased TLR4 could lead to reduced expression of VEGF. The RT-qPCR analysis shows that indeed VEGF transcripts were downregulated in diabetic wounds compared to control wounds ( $\mathrm{p}$ value $=<0.0001$, mean fold change $=-1.39$, Standard error of mean $=0.10$ ) (Figure 2). To determine if the difference in the message of TLR4 translates to the similar difference in protein, equivalent amount of DFU and control samples were analyzed by Western blot using TLR4 monoclonal antibody. DFU samples showed significant reduction of TLR4 protein as compared to controls ( $\mathrm{p}$ value $=<0.0001$ ) (Figure 3, Supplementary Figures $1 \mathrm{~A}$ and $1 \mathrm{~B}$ ). To evaluate if the TLR4 expression was influenced by wound grade, infection status or gender of the subject, TLR4 transcript was compared between different subjects. There was no correlation of TLR4 transcripts observed with the wound grade ( $\mathrm{p}$ value $>0.05$ ) (Figure $4 \mathrm{~A}$ ) or with the infection (Figure $4 \mathrm{~B}$ ); however males showed significantly lesser amount of TLR4 mRNA transcripts with respect to females ( $p$ value $=0.02)$ (Figure $4 \mathrm{C})$.

To further understand the mechanism of down-regulation of TLR4, we hypothesized that DNA Methylation which is an important regulator of gene expression could have been impacted leading to the ultimate downregulation of TLR4. Therefore, Methylation status of TLR4 promoter was analyzed in DFU and control wounds by semiquantitaive PCR using specific primers for TLR4 after methylation-sensitive restriction enzyme digestion of genomic DNA. Methylation pattern analysis of diabetic wounds revealed $74 \%$ of them contained methylated $\mathrm{CpG}$ at -822 and -646 positions near a TATA box located close to the $\mathrm{Sp}-1$ sites in the promoter of TLR4 compared to non diabetic control wounds containing only $50 \%$ methylated $\mathrm{CpG}$ (Figures 5A-5C). Thus, higher methylation of TLR4 promoter in DFU with respect to controls was observed.

\section{Discussion}

TLR4 is associated with induction of a wide spectrum of cytokines [7]. Studies on $\mathrm{C} 3 \mathrm{H} / \mathrm{HeJ}$ and $\mathrm{C} 57 \mathrm{BL} 10 / \mathrm{ScCr}$ mice have established that lipopolysaccharides of bacterial origin are potentially recognized by TLR4 $[23,24]$. In response to microbial stimuli, TLR4 mediates the secretion of antimicrobial peptide in the epithelial cells. Low levels of TLR4 may be correlated with a reduced and persistent inflammatory response and an inefficient clearance of pathogenic microorganisms [25]. As a receptor TLR4 entertains a wide spectrum of endogenous and exogenous ligands like HSP60, HSP70, fibronectine, oligosaccharides and S100A8, thus modulating an effector function of these ligands [26].

Current findings indicate a significant down regulation of TLR4 mRNA in wounds of DFU patients compared to wounds of non diabetic

A

ttcaagggcctagggaaaggggaaatggggagttatttattaatgaatagtggtgatgattgtacaaaaatatgaacataattaatgccactaaattg tncacatacaaatggtcaagataataaattttatgttatgtcatgttatgttatgtgattttaccataatacagaaaatgaaaaaagaaaagaaagaaa gtaaagcttagcggtttncatgacttgnccaatgcctcaaagccatgagtcgacccagctgagatctgancttcagtatattccattctgaaatcccag actttcccaatcttcttgtactttcaaactgtgtttcagttgaggtttattttcagttttgtatgtgagtttcttcgcaagaaggg cgggccaaattgtgtc ctgcaaaaacctacatatcg

B

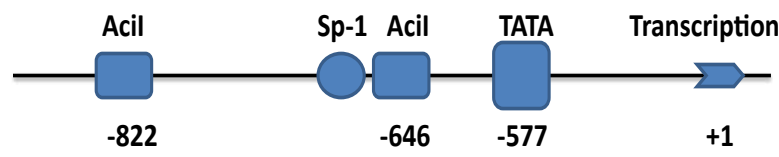

Primer forward Primer reverse

$393 \mathrm{bp}$

Figure 1: Schematic diagram of the promoter of human toll-like receptor (TLR) 4 gene is represented with (A) Genomic sequence of the TLR4 promoter region ranging from -1038 bp to - 611 bp (GenBank accession number AF172169) with CpG sites studied in bold and underlined. (B) Representative diagram of the human TLR4 promoter. Transcription factor ( $\mathrm{sp}-1)$ binding site is indicated as a circle. Cut site for restriction enzyme Acil are represented as rectangles. 
$\begin{array}{llllllllllllll}\text { C6 } & \text { C5 } & \text { C4 } & \text { C3 } & \text { C2 } & \text { C1 } & \text { M } & \text { P1 } & \text { P2 } & \text { P3 } & \text { P4 } & \text { P5 } & \text { P6 } & \text { P7 }\end{array}$
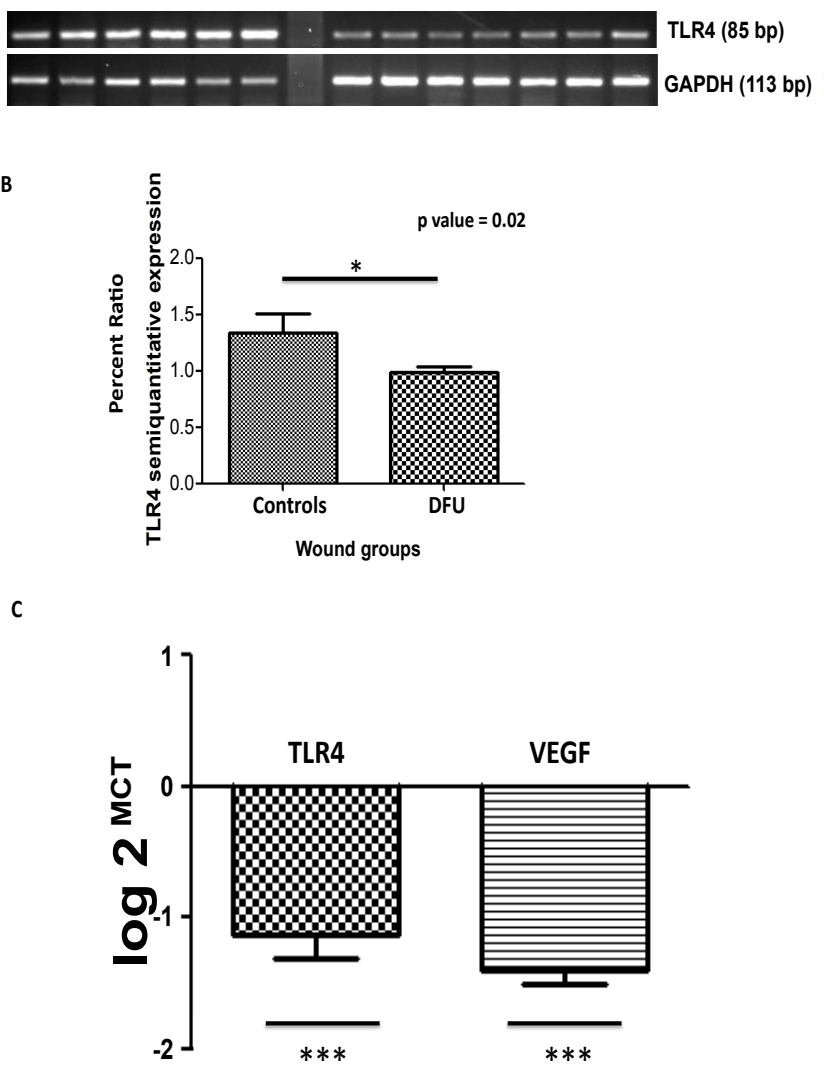

Figure 2: Semi-quantitative reverse transcriptase polymerase chain reaction (RT-PCR) analysis in 78 DFU cases and 8 controls. RNA was isolated from wound samples collected during debridement of DFU patients and controls, cDNA was synthesized and RT-PCR for TLR4 and GAPDH was performed.

(A) Representative picture of controls $\{C\}$ and DFU $\{P\}$ in each group is shown. (B) Bar Graph represents the percent ratio which was calculated for the expression of TLR4 and GAPDH in Controls and DFU respectively. The percent ratio was determined by dividing the band intensity of TLR4 by GAPDH. Unpaired t test was used to check the difference between the mean values of TLR4 mRNA in DFU and control subjects. A two tailed $p$ value < 0.05 was considered as statistically significant. Semi quantitative RT-PCR analysis shows the reduced expression of TLR4 transcripts in DFU patients ( $p$ value $=0.02, t=2.28$, mean change in percent ratio $=0.99$, Standard error of mean=0.04)

(C) Representative graph showing Quantitative Real-time PCR analysis showing the reduced expression of TLR4 mRNA and VEGF in wounds of DFU patients. Analysis was done in randomly selected 43 DFU cases and 8 controls. Fold change in expression of genes was determined using the $\Delta \triangle C T$ method of relative quantification. Firstly normalization of the resulting threshold cycle (CT) values of the target gene was done with the CT values of the internal control GAPDH in the same samples $(\triangle C T=C T$ target $-C T$ GAPDH). It was again normalized with the control $(\triangle \triangle C T=\Delta C T-\Delta C T$ control). The fold change in the expression was then calculated $\left(2^{-\Delta \Delta C T}\right)$. The graph was plotted using log $2^{-\triangle \Delta C T}$. The graph clearly showed that TLR4 was decreased significantly in the wounds of T2DM cases ( $p$ value $=<0.0001$, mean fold change $=-1.13$, Standard error of mean $=0.17$ ). Similar down regulation was showed by the VEGF mRNA ( $p$ value $=<0.0001$, mean fold change $=-1.39$, Standard error of mean $=0.10$ ).

patients. This was in consistent with previous studies in animal models that intact TLR4-MyD88 signaling is required for accelerated wound healing [15]. TLR4 is instrumental in maintaining tissue homeostasis by balancing the rates of tissue repair and regeneration. This process of tissue repair is assisted by one of its adaptor molecule, MyD88. TLR4-MyD88 dependent pathway is shown to have a protective role against intestinal injury when treated with DSS in a mice model [27]. In absence of TLR4 or its ligands like hyaluron, there is an increased rate of lung injury along with less recruitment of inflammatory cells [28]. MyD88 plays an important role in restoration of liver following a partial hepactectomy during early phase of regeneration by regulating the influx of macrophages [7]. Therefore reduced expression of TLR4 in DFU patients could lead to insufficient signaling via TLR4-MyD88 pathway leading to impaired wound healing and ulcer progression.

Comparison of different grades of DFU with TLR4 mRNA expression suggested that there was no change in TLR4 level along with increase in the wound grade to guide the wound to a proper healing cascade. Moreover the infection status of wounds in DFU cases suggested that the TLR4 mRNA expression also did not changed with presence or absence of infection due to the mitigating effect of persistent hyperglycemia in diabetic subjects. Among DFU patients females showed increased amount of TLR4 mRNA expression compared to male, which was accordance to the available literature that TLR4 expression is modulated by female hormones like estrogens [29]. TLR4 expression modulation by estrogens may be one of the reasons for less incidence of DFU in females than that observed in males. In the present study a higher methylation status of TLR4 promoter was observed in the wounds of DFU patients with respect to controls.

TLR4 is involved in almost all phases of a wound healing cascade. In Initial inflammatory phase, there is TLR4 mediated induction of inflammatory cytokines [30]. This short inflammatory phase is required for attracting cells like macrophages in the wound milieu so that proliferative phase may be initiated. The inflammatory phase also consists of the TLR4 mediated control over microbiota in the wound surrounding. The PAMPs over pathogens and DAMPs secreted by necrotic tissue serve as the initiating signal for TLR4 mediated inflammatory phase in wound healing process [31]. TLR4 also mediates the proliferative phase of wound healing by regulating the

\section{$p$ value $<0.0001$}

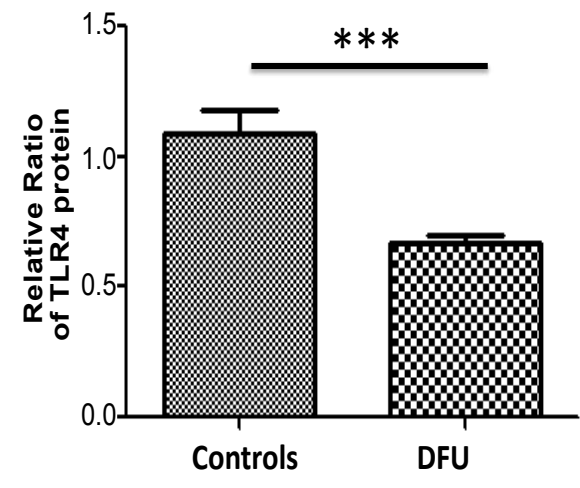

Wound groups

Figure 3: TLR4 protein expression was analyzed in 43 DFU patients and 8 controls. Tissue samples collected during debridement process from control $\{C\}$ and DFU patients $\{P\}$ were homogenized and Western blot analysis was performed for expression of TLR4 and GAPDH protein. Alpha Imager 2200 software version 3.1.2 was used to quantify band density. The relative percent ratio of protein (TLR4 vs. GAPDH) was calculated. Unpaired $t$ test was used to check the difference between the mean values of TLR4 protein in DFU and control subjects using Graph Pad Prism. A two tailed $p$ value $<0.05$ was considered as statistically significant. Bar Graph showing down regulation of TLR4 protein in wounds of T2DM patients compared to controls ( $p$ value $=<0.0001$, difference between means $=0.42$, Standard error of mean=0.08). 
Citation: Kanhaiya, Agrawal NK, Gupta SK, Kiran Singh (2013) Differential Expression of Toll like Receptor 4 in Type 2 Diabetic Patients with Impaired Wound Healing. J Diabetes Metab 4: 260. doi:10.4172/2155-6156.1000260

Page 5 of 6

keratinocytes present at wound edges. These activated keratinocytes then proliferate and migrate to the wound bed [6]. TLR4 mediate the expression of growth factors like ECF, VEGF in the epidermal layer beside the wound edge which are essential for an efficient wound healing process $[32,33]$. Angiogenesis, the process of revascularization of the wound bed is controlled by the TLR4-MyD88 mediated regulation of growth factors like VEGF [13]. The study reported here demonstrates significant down-regulation of VEGF mRNA transcripts in diabetic wounds compared to controls. This further supports our hypothesis that TLR4 via its downstream molecules play an important role in wound repair and any imbalance in members of TLR4 pathway may lead to compromised wound healing cascade in T2DM patients.

T2DM patients generally are not able to mount an adequate inflammatory response due to compromised ability to fight infection $[34,35]$. This inability may be correlated with impaired expression and action of TLR4 in case of T2DM individuals leading to impaired wound healing and development of DFU in T2DM patients.

\section{Author Contribution}

Kanhaiya designed research, performed experiments, collected and
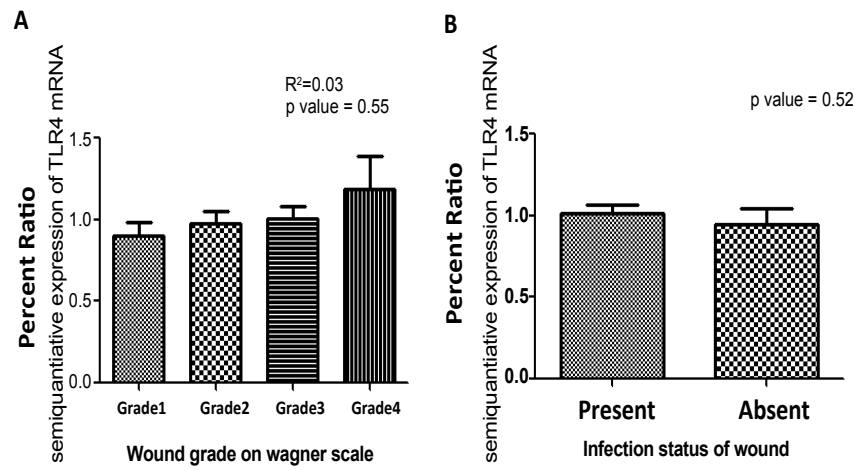

C

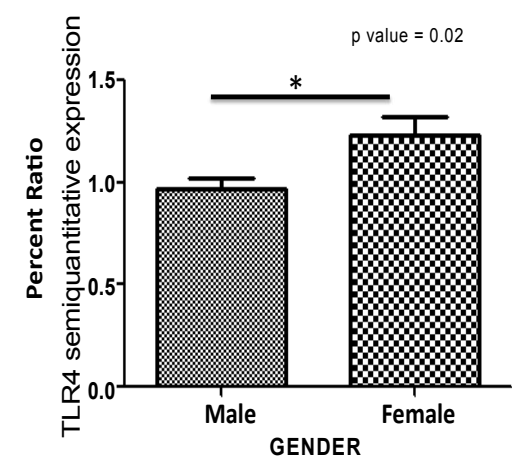

Figure 4: Bar Graph showing the comparison of Semiquantitaive TLR4 mRNA expression with: (A) wound grades on wagner scale, (B) Presence or absence of Infection and (C) Gender of DFU patients. Unpaired t test was used to check the difference between the mean values of TLR4 mRNA in male and female subjects using Graph Pad Prism. One way analysis of variance (ANOVA) test was used to check the differences between means of TLR4 mRNA expression between (i) different wound grades and (ii) infected and non infected wounds. A two tailed $p$ value $<0.05$ was considered as statistically significant Expression of TLR4 mRNA was found to be not dependent on either wound grade or infection status of the wounds ( $p$ value $>0.05$ ). Among the diabetic wounds, males showed relatively lesser amount of TLR4 mRNA transcripts with respect to females ( $p$ value $=0.02, t=2.3$, mean percent ratio in males $=0.97$ \pm 0.05 , mean percent ratio in females $=1.23 \pm 0.08$ ).
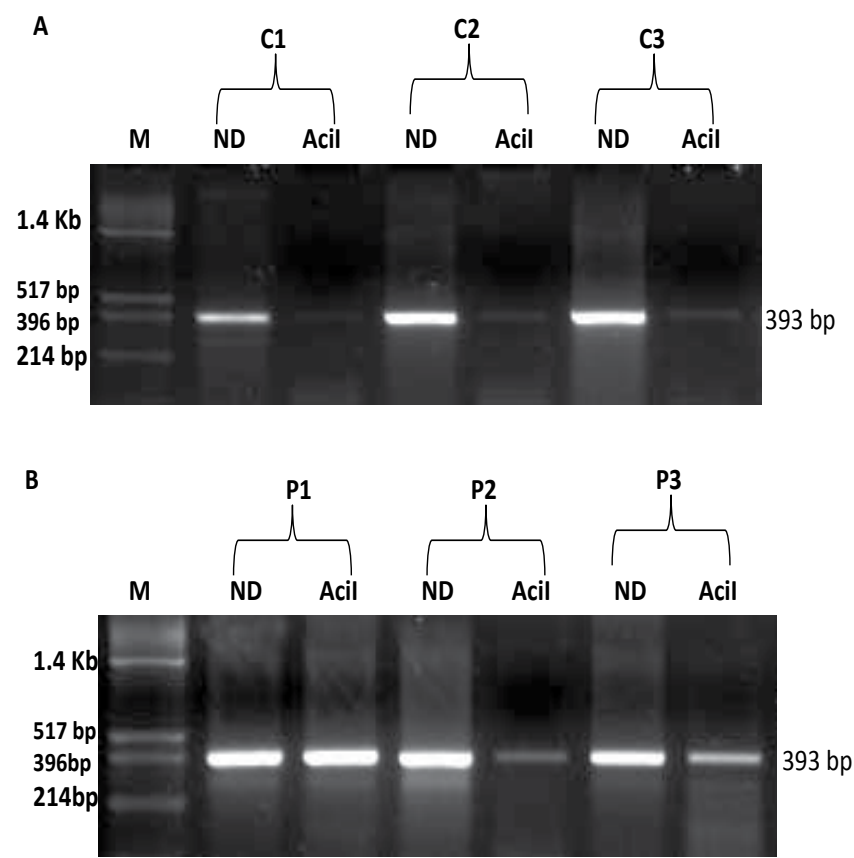

C

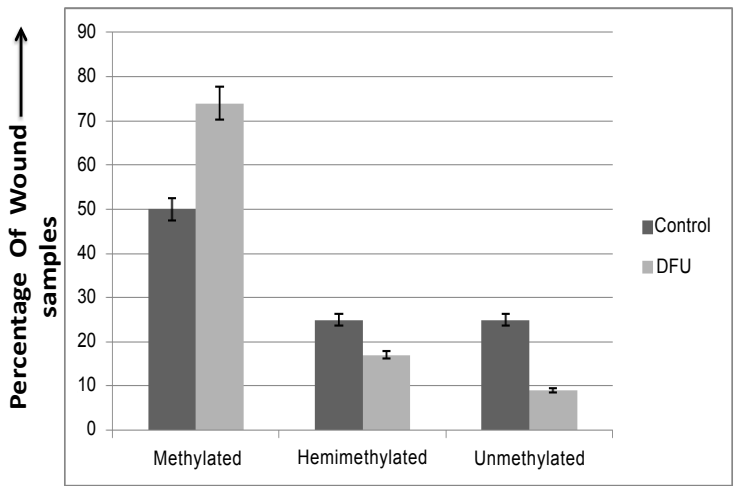

Methylation status of TLR4 promoter

Figure 5: Methylation analysis of the TLR4 gene promoter in the wounds of DFU patients and controls was done. Bands of $(A)$ control $\{C\}$ samples and (B) DFU samples $\{P\}$ were obtained after polymerase chain reaction of TLR4 (393 bp); (ND) indicates non-digested DNA samples, followed by digested DNA samples. (C) Bar graph showing methylation frequency of the Acil sites in TLR4 promoter in controls compared to DFU patients. Methylation pattern analysis of diabetic wounds revealed $74 \%$ of them contained methylated CpG at -822 and -646 positions near a TATA box located close to the Sp-1 sites in the promoter of TLR4 compared to non diabetic control wounds containing only $50 \%$ methylated $\mathrm{CpG}$.

analyzed the data, wrote the paper. K.S. designed research, interpreted data, and wrote the paper. N.K.A. and S.K.G. provided blood and tissue samples and did the clinical evaluation of patients. Their critical comments helped us in writing the manuscript. Dr. Kiran Singh is the guarantor of this work, had full access to all the data, and takes full responsibility for the integrity of data and the accuracy of data analysis.

\section{Acknowledgement}

This work was funded by Department of science and technology, New Delhi, India. Financial assistance by Department of Biotechnology, Ministry of Science and Technology, New Delhi, India in form of Senior Research fellowship to the first author is thankfully acknowledged. 
Citation: Kanhaiya, Agrawal NK, Gupta SK, Kiran Singh (2013) Differential Expression of Toll like Receptor 4 in Type 2 Diabetic Patients with Impaired Wound Healing. J Diabetes Metab 4: 260. doi:10.4172/2155-6156.1000260

\section{References}

1. Jeffcoate WJ, Harding KG (2003) Diabetic foot ulcers. Lancet 361: 1545-1551.

2. Reiber GE, Vileikyte L, Boyko EJ, del Aguila M, Smith DG, et al. (1999) Causa pathways for incident lower-extremity ulcers in patients with diabetes from two settings. Diabetes Care 22: 157-162.

3. Werner S, Grose R (2003) Regulation of wound healing by growth factors and cytokines. Physiol Rev 83: 835-870.

4. Singer AJ, Clark RA (1999) Cutaneous wound healing. N Engl J Med 341 738-746.

5. Calvin M (1998) Cutaneous wound repair. Wounds 10: 12-32

6. Chen L, Guo S, Ranzer MJ, DiPietro LA (2013) Toll-like receptor 4 has an essential role in early skin wound healing. J Invest Dermatol 133: 258-267.

7. Medzhitov R, Preston-Hurlburt P, Janeway CA Jr (1997) A human homologue of the Drosophila Toll protein signals activation of adaptive immunity. Nature 388: 394-397.

8. Hansson GK, Edfeldt K (2005) Toll to be paid at the gateway to the vessel wall. Arterioscler Thromb Vasc Biol 25: 1085-1087.

9. Belvin MP, Anderson KV (1996) A conserved signaling pathway: the Drosophila toll-dorsal pathway. Annu Rev Cell Dev Biol 12: 393-416.

10. Lemaitre B, Nicolas E, Michaut L, Reichhart JM, Hoffmann JA (1996) The dorsoventral regulatory gene cassette spatzle/Toll/cactus controls the potent antifungal response in Drosophila adults. Cell 86: 973-983.

11. Seki E, Tsutsui H, limuro Y, Naka T, Son G, et al. (2005) Contribution of Toll-like receptor/myeloid differentiation factor 88 signaling to murine liver regeneration. Hepatology 41: 443-450.

12. Vink A, Schoneveld AH, van der Meer JJ, van Middelaar BJ, Sluijter JP, et al. (2002) In vivo evidence for a role of toll-like receptor 4 in the development of intimal lesions. Circulation 106: 1985-1990.

13. Grote K, Schütt H, Schieffer B (2011) Toll-like receptors in angiogenesis ScientificWorldJournal 11: 981-991.

14. Mollen KP, Anand RJ, Tsung A, Prince JM, Levy RM, et al. (2006) Emerging paradigm: toll-like receptor 4 -sentinel for the detection of tissue damage. Shock 26: $430-437$.

15. Macedo L, Pinhal-Enfield G, Alshits V, Elson G, Cronstein BN, et al. (2007) Wound healing is impaired in MyD88-deficient mice: a role for MyD88 in the regulation of wound healing by adenosine A2A receptors. Am J Pathol 171 : 1774-1788.

16. Bao P, Kodra A, Tomic-Canic M, Golinko MS, Ehrlich HP, et al. (2009) The role of vascular endothelial growth factor in wound healing. J Surg Res 153 : 347-358.

17. Stojadinovic OKA, Golinko M, Tomic-Canic M (2007) A novel, non-angiogenic mechanism of VEGF: stimulation of keratinocyte and fibroblast migration. Wound Repair and Regeneration: A30

18. Botero TM, Shelburne CE, Holland GR, Hanks CT, Nör JE (2006) TLR4 mediates LPS-induced VEGF expression in odontoblasts. J Endod 32: 951955
19. Pei Z, Lin D, Song X, Li H, Yao H (2008) TLR4 signaling promotes the expression of VEGF and TGFbeta1 in human prostate epithelial PC3 cells induced by lipopolysaccharide. Cell Immunol 254: 20-27.

20. Wagner FW Jr (1981) The dysvascular foot: a system for diagnosis and treatment. Foot Ankle 2: 64-122.

21. Gireesh G, Kumar TP, Mathew J, Paulose C (2009) Enhanced muscarinic M1 receptor gene expression in the corpus striatum of streptozotocin-induced diabetic rats. J Biomed Sci 16: 38.

22. De Oliveira NF, Andia DC, Planello AC, Pasetto S, Marques MR, et al. (2011) TLR2 and TLR4 gene promoter methylation status during chronic periodontitis. $\mathrm{J}$ Clin Periodontol 38: 975-983.

23. Poltorak A, He X, Smirnova I, Liu MY, Van Huffel C, et al. (1998) Defective LPS signaling in $\mathrm{C} 3 \mathrm{H} / \mathrm{HeJ}$ and $\mathrm{C} 57 \mathrm{BL} / 10 \mathrm{ScCr}$ mice: mutation in TIr4 gene. Science 282: $2085-2088$.

24. Qureshi ST, Larivière L, Leveque G, Clermont S, Moore KJ, et al. (1999) Endotoxin-tolerant mice have mutations in Toll-like receptor 4 (TIr4). J Exp Med 189: 615-625.

25. Hoshino K, Takeuchi O, Kawai T, Sanjo H, Ogawa T, et al. (1999) Cutting edge: Toll-like receptor 4 (TLR4)-deficient mice are hyporesponsive to lipopolysaccharide: evidence for TLR4 as the Lps gene product. J Immunol 162: $3749-3752$

26. Takeda K, Kaisho T, Akira S (2003) Toll-like receptors. Annu Rev Immunol 21 335-376.

27. Pull SL, Doherty JM, Mills JC, Gordon JI, Stappenbeck TS (2005) Activated macrophages are an adaptive element of the colonic epithelial progenitor niche necessary for regenerative responses to injury. Proc Natl Acad Sci U S A 102 99-104.

28. Gurtner GC, Werner S, Barrandon Y, Longaker MT (2008) Wound repair and regeneration. Nature 453: 314-321.

29. Rettew JA, Huet YM, Marriott I (2009) Estrogens augment cell surface TLR4 expression on murine macrophages and regulate sepsis susceptibility in vivo. Endocrinology 150: 3877-3884.

30. Smiley ST, King JA, Hancock WW (2001) Fibrinogen stimulates macrophage chemokine secretion through toll-like receptor 4. J Immunol 167: 2887-2894.

31. Kluwe J, Mencin A, Schwabe RF (2009) Toll-like receptors, wound healing, and carcinogenesis. J Mol Med (Berl) 87: 125-138.

32. Chen JD, Kim JP, Zhang K, Sarret Y, Wynn KC, et al. (1993) Epiderma growth factor (EGF) promotes human keratinocyte locomotion on collagen by increasing the alpha 2 integrin subunit. Exp Cell Res 209: 216-223.

33. Rheinwald JG, Green H (1977) Epidermal growth factor and the multiplication of cultured human epidermal keratinocytes. Nature 265: 421-424.

34. Goren I, Müller E, Pfeilschifter J, Frank S (2006) Severely impaired insulin signaling in chronic wounds of diabetic ob/ob mice: a potential role of tumor necrosis factor-alpha. Am J Pathol 168: 765-777.

35. Falanga $\vee(2005)$ Wound healing and its impairment in the diabetic foot. Lance 366: $1736-1743$ 